\title{
ANALISIS VISUAL GRAPHICAL USER INTERFACE (GUI) WEBSITE UNIVERSITAS NEGERI EKS. IKIP: BAHAN PENGEMBANGAN MATERI AJAR DESAIN KOMUNIKASI VISUAL BERBASIS PENDIDIKAN KARAKTER
}

\author{
Elly Herliyani ${ }^{1}$, Jajang Suryana ${ }^{2}$, Ketut Nala Hari Wardana ${ }^{3}$ \\ Program Studi Desain Komunikasi Visual \\ Fakultas Bahasa dan Seni, Universitas Pendidikan Ganesha \\ Jalan Jend. A. Yani 67 Singaraja 81116, Telp. 0362-21541, Fax. 0362-27561 \\ Email: elly.herliyani@undiksha.ac.id ${ }^{1}$, jajang.suryana@undiksha.ac.id ${ }^{2}$, nala.hari@undiksha.ac.id ${ }^{3)}$
}

\begin{abstract}
This is a descriptive analysis research. The data examined were the conditions of visual dan functional of the content of an interface (GUI, graphical user interface) of the state university websites of former IKIP: UPI, UNY, UNNES, UNESA, and UM. Five of these universities, in the rank period of January - June 2014 by webometrics and 4ICU, were the top 20 in national level. The website UNIDKSHA was used in the comparative analysis of the materials for the input concerning the condition of UNDIKSHA website. The comparison result will be used in developing the material of Visual Communication Design course.

The result of the research showed that the interface of the six universities websites had interesting view for visitors. The menus and sub menus are provided on page interfaces, all have links to the respective faculty sub web, web journals and the database of scientific work of the lecturers. In line with one of rank patterns of Webometrics and 4ICU, it seems that the spatial information of scientific report (e.g. research results, scientific articles, and the dissemination of scientific results) still had less attention from some web managers as the objects of the study. The service provided and direct download pattern set at any information that is accessed by a visitor was regarded unsatisfying to visitors, as well as the information provided was likely incomplete.
\end{abstract}

Key words: interface, website, Visual Communication Design.

\begin{abstract}
ABSTRAK
Penelitian ini penelitian deskriptif analitis. Data yang diteliti berupa kondisi visual dan fungsional isi antarmuka (Graphical User Interface) website Perguruan Tinggi Negeri (PTN) eks IKIP, di antaranya adalah: website UPI, UNY, UNNES, UNESA, dan UM. Lima PTN pada periode perangkingan Januari-Juni 2014 oleh Webometrics dan 4ICU, berada pada peringkat 20 besar tingkat Nasional. website Undiksha dijadikan bahan analisis pembanding dimaksudkan untuk menetapkan masukan terkait dengan kondisi website Undiksha. Hasil pembandingan akan menjadi bahan pengembangan materi ajar mata kuliah Desain Komunikasi Visual.

Hasil penelitian menunjukkan bahwa interface website keenam perguruan tinggi eks IKIP memiliki tampilan yang cukup menarik bagi pengunjung. Menu dan sub menu yang disediakan di halaman interface, semua dilengkapi dengan links ke masing-masing sub-web fakultas, jurnal, dan database karya ilmiah dosen. Sejalan dengan salah satu pola perankingan yang ditetapkan Webometrics dan 4ICU, tampaknya agihan (membagi, memberi) informasi ilmiah, seperti: laporan hasil penelitian, artikel ilmiah, dan diseminasi hasil temuan ilmiah, masih kurang mendapat perhatian beberapa pengelola website sasaran penelitian ini. Cara layanan yang disediakan, pola unduhan langsung pada setiap informasi yang ingin diakses kurang memuaskan pengguna. Begitupun informasi yang disediakan cenderung masih belum lengkap.
\end{abstract}

Kata kunci: antarmuka, website, Desain Komunikasi Visual. 


\section{PENDAHULUAN}

Salah satu layanan dalam sistem operasi perangkat lunak komputer yang disediakan untuk pengguna adalah interface (antarmuka). Antarmuka bisa diibaratkan sebagai sebuah area atau wilayah tempat bertemunya pengguna dengan (pe)layan(an) sistem operasi. Website adalah sebuah sistem operasi (dalam tulisan ini penyebutan website berarti menunjuk sistem operasi). Oleh karena itu, kelengkapan layanan yang ditampilkan dalam antarmuka yang berbentuk graphical user interface (GUI) menjadi sangat penting. Kenyamanan pengguna dalam memilih dan merespon informasi yang disediakan oleh pemilik website, banyak ditentukan di ruang antarmuka.

Keberadaan website sebagai bentuk layanan data, lebih khusus layanan data lembaga pendidikan, penting sebagai bahan bahasan. Dalam konteks desain komunikasi visual, website adalah salah satu bentuk media komunikasi yang ditampilkan secara visual. Oleh karena itu, hal-hal visual menjadi penting dalam tampilan GUI sebuah website. Bahkan bisa diperkirakan, GUI memiliki peran yang sangat penting dalam mengundang banyaknya jumlah pengunjung sekaligus pengguna sebuah website. Kemudahan akses dan kelengkapan layanan di ruang GUI adalah salah satu tuntutan yang diharapkan oleh pengunjung ketika melakukan pencarian data.

Jumlah pengunjung sebuah website telah menjadi salah satu standar dalam penilaian "ketenaran" sebuah website. Webometrics adalah salah satu lembaga yang dianggap cukup bergengsi dalam menetapkan standar penilaian ranking perguruan tinggi. Berikut ini adalah catatan tentang 20 Besar Universitas Tertenar di Indonesia Versi Webometrics dan 4ICU per Januari 2014.

Ranking perguruan tinggi versi webometrics.info Januari 2014, yaitu: (1) Universitas Gadjah Mada. (2) Institute of Technology Bandung. (3) Universitas Indonesia. (4) Airlangga University. (5) Universitas Padjajaran. (6) Brawijaya University. (7) Diponegoro University. (8) Bogor Agricultural University.
(9) Institut Teknologi 10 November. (10) Gunadarma University. (11) Hasanuddin University. (12) Petra Christian University. (13) Universitas Islam Indonesia. (14) Universitas Pendidikan Indonesia. (15) Universitas Sebelas Maret. (16) Bina Nusantara BINUS University. (17) Universitas Muhammadiyah Yogyakarta. (18) Universitas Mercu Buana. (19) Universitas Negeri Semarang. (20) Universitas Sriwijaya (CSIC, http://www.webometrics.info/en/asia/indonesia, diakses 13 Maret 2014, pukul 16:05)

Ranking perguruan tinggi versi $4 \mathrm{icu}$. org Januari 2014, yaitu: (1) Institut Teknologi Bandung. (2) Universitas Gadjah Mada. (3) Universitas Indonesia. (4) Universitas Brawijaya. (5) Universitas Sebelas Maret. (6) Universitas Diponegoro. (7) Universitas Padjadjaran. (8) Universitas Gunadarma. (9) Institut Pertanian Bogor. (10) Universitas Airlangga. (11) Universitas Bina Nusantara. (12) Universitas Mercu Buana. (13) Universitas Hasanuddin. (14) Institut Teknologi Sepuluh Nopember. (15) Universitas Muhammadiyah Yogyakarta. (16) Universitas Negeri Yogyakarta. (17) Universitas Pendidikan Indonesia. (18) Universitas Katolik Indonesia Atma Jaya. (19) Universitas Negeri Semarang. (20) Universitas Islam Indonesia (Fatuzzo, http:// www.4icu.org/id/, diakses 13 Maret 2014, pukul 16:31).

Penelitian ini dilakukan untuk keperluan mengetahui tampilan GUI PTN eks IKIP. Melalui analisis visual GUI website masingmasing, diharapkan bisa tergambar kelebihankelebihan sarana dan menu layanan data yang disajikan. Tim peneliti menempatkan diri sebagai pengguna sekaligus expert yang bisa mendapatkan pengalaman langsung dari penggunaan layanan website dimaksud. Sehingga, hasil analisis tentang kelebihan masingmasing website bisa menjadi bahan pengembangan materi ajar Desain Komunikasi Visual. Berdasarkan latar belakang masalah di atas dapat dirumuskan sebagai berikut: (1) Bagaimanakah tampilan visual GUI websitePTN eks. IKIP periode Januari - Juni tahun 2014? (2) Sarana apa saja yang disediakan oleh pengelola website PTN eks. IKIP dalam 
melayani keperluan pengunjung? (3) Menu layanan data apa saja yang dipasang di halaman GUI website PTN eks. IKIP? Dan (4) Bagaimana desain pola sajian halaman $G U I$ website UM, UPI, UNNES, UNY, UNESA, dan Undiksha Januari-Juni tahun 2014?

Sesuai dengan rumusan permasalahan tersebut, maka yang menjadi tujuan penelitian ini adalah: (1) Mendeskripsikan tampilan visual GUI website PTN eks. IKIP periode Januari-Juni tahun 2014. (2) Mendeskripsikan sarana apa saja yang disediakan oleh pengelola website PTN eks. IKIP dalam melayani keperluan pengunjung. (3) Mendeskripsikan hasil analisis visual menu layanan data apa saja yang dipasang di halaman GUI websitePTN eks. IKIP. Dan (4) Membandingkan desain pola sajian halaman GUI website UM, UPI, UNNES, UNY, UNESA, dan Undiksha Januari-Juni tahun 2014.

Graphical User Interface (GUI) adalah sebagai sarana atau medium atau sistem operasi yang digunakan untuk menghubungkan antara perangkat mikroprosesor agar dapat berkomunikasi dengan pengguna (user) (M. Husnul Maarif, http://rahmanrobotic1508. blogspot.com, diakses 10 Maret 2014).

Website sebuah lembaga, termasuk lembaga perguruan tinggi, telah menjadi tren sekaligus kebutuhan. Agihan (sharing) informasi, tak bisa dihindarkan, memerlukan sarana yang mudah dijangkau dan "tak berbatas". Jaringan internet telah bisa menyediakan hampir semua keperluan tersebut. Agar disukai banyak pengunjung, wajah sebuah lembaga bisa ditampilkan dalam GUI website dengan tampilan yang menarik dan tawaran layanan data yang mudah diakses.

Rancangan media komunikasi website mengikuti sejumlah pola desain yang telah dianggap sebagai konvensi. Pola desain yang umum digunakan di antaranya adalah pola air terjun dan pola spiral. Pola desain air terjun adalah pola klasik yang menggambarkan pola aliran data yang mengalir sistematis dan berurutan. Sementara itu, pola spiral menggunakan pola aliran data yang mengalir dan berbalik sesuai dengan terminal data yang ditetapkan. Ruang-ruang tertentu dalam pengelolaan informasi, dirancang sejalan dengan pola tawaran sajian data yang diupayakan selalu ter-update agar menarik bagi para pengguna. Dengan demikian, desain website bisa mengikuti tren dan keberlangsungan agihan informasi.

Fitur-fitur yang ditampilkan di ruang antarmuka website diatur dalam pilihanpilihan tombol menu (dan submenu) yang beragam. Ruang Beranda (biasanya ruangan depan, antarmuka website, diberi nama beranda atau home) menjadi ruang utama. Dari Beranda, pengunjung bisa memasuki ruangan lainnya sejalan dengan menu dan submenu navigasi yang disediakan oleh pemilik website. Site map atau daftar isi menjadi sangat penting karena akan sangat membantu dalam proses pencarian link yang hendak dituju oleh pengunjung (Juju \& Syukrie, 2009).

Posisi fitur navigasi bervariasi. Ada navigasi yang ditempatkan di atas (top navigation), untuk website yang memiliki banyak menu dan fasilitas. Navigasi jenis ini cukup menghemat tempat, biasanya disusun dalam pola teks tanpa ikon atau image. Posisi navigasi lainnya adalah di kiri (left navigation), di kanan (right navigation), dan navigasi bebas (free navigation). Jenis navigasi yang disebutkan terakhir, lebih cocok untuk website yang menggunakan animasi flash (Purnama, 2004).

LPTK (Lembaga Pendidikan Tinggi Keguruan) yang dahulu lebih dikenal dengan sebutan IKIP, adalah lembaga yang menghasilkan calon-calon guru. Melalui proses konversi tahun 1999, kini, IKIP-IKIP Negeri telah berubah nama menjadi universitas. Perubahan tersebut, selain mengubah nama sebutan, juga menuntut perubahan orientasi visi dan misinya. Konversi dari IKIP ke Universitas telah membawa perubahan orientasi yang tak hanya melulu mencetak para guru dan pendidik saja, sehingga semua eks-IKIP dapat bergerak dengan bebas untuk memenuhi kebutuhan masyarakat memilih berbagai disiplin ilmu (Sirat, http://rudinisirat.blogspot.com).

Sembilan IKIP yang "dipaksa" untuk berubah menjadi universitas adalah IKIP Negeri Jakarta, Bandung, Semarang, Yogyakarta, Surabaya, Malang, Padang, Medan, dan 
Makasar. Menyusul 2 IKIP berikutnya yaitu IKIP Negeri Gorontalo dan Singaraja. Perubahan tersebut tidak serta merta mengubah semua namanya menjadi universitas (negeri) ditambah nama lokasinya, ada dua eks IKIP yang masih mempertahankan unsur sebutan pendidikan dalam nama barunya, yaitu Universitas Pendidikan Indonesia (eks. IKIP Bandung) dan Universitas Pendidikan Ganesha (eks. IKIP Singaraja).

Melalui penilaian Webometrics dan 4ICU, beberapa PTN eks IKIP ternyata telah bisa sejajar dengan perguruan tinggi umum. Kesejajaran tersebut dicapai melalui banyak hal, bukan sekadar pengukuran terhadap kemampuan lulusan semata. Website sebagai gambaran kondisi sebuah perguruan tinggi, telah digunakan menjadi sarana pengukuran kondisi pemiliknya. Di antara yang menjadi bahan pengukuran adalah masalah rating pengunjung, jumlah rujukan terhadap website, kualitas dan kuantitas hasil penelitian yang diupload melalui website perguruan tinggi dimaksud.

\section{METODE}

Penelitian ini adalah penelitian deskriptif analitik. Data awal berupa tampilan GUI website PTN eks. IKIP. GUI yang menjadi ruang komunikasi antara pemilik website dengan pengguna adalah bagian penting dari sebuah website. Ia menjadi daya tarik bagi pengguna. Tawaran fitur dan menu yang dipajang di ruangan $G U I$ ini merupakan gambaran petunjuk jalan bagi pengguna untuk mendatangi tempat penyimpanan data yang telah disiapkan oleh pemilik website. Oleh karena itu, bagian GUI inilah yang menjadi sorotan utama dalam penelitian ini.

Analisis visual terhadap GUI website PTN eks. IKIP ini menyangkut pertanyaanpertanyaan yang diadaptasi dari pola pertanyaan Poster/Visual Analysis Worksheet yang dikembangkan oleh Serianz (2005) dari The NARA Photo Analysis Sheet (http:// www.archives.gov/digital classroom/lessons/ analysis_worksheets/document.html), mengemukakan bahwa pertanyaannya menyangkut:
(1) What are the main colors used in the visual? (2) What symbols (if any) are used in the visual? (3) If a symbol is used, is it (- clear and easy to understand?; - attention-grabbing and memorable?). (4) Are words used in the visual? If so what words? (5) Is the message in the visual mostly found in words, pictures, or both? (6) Who probably created the visual? (7) Who do you think was meant to see this visual? Who was the intended audience? (8) Was there something the creator was hoping people would do after seeing the visual? if is, what was it? (9) the most effective visuals use symbols, words, or pictures that are unusual, memorable, simple, and direct. Is this an effective visual? Why or why not? dan (10) Is there anything you would change that you think would make the visual even more effective? If so what?

Pertanyaan-pertanyaan tadi akan dilengkapi dengan unsur analisis visual lainnya berupa analisis tentang komposisi, penempatan tombol menu, pemetaan jalur informasi, kemudahan penggunaan dan penyelesaian suatu kegiatan pemanfaatan informasi, dan masalah ergonomis hasil rancangan.

Sasaran penelitian ini adalah GUI website PTN eks. IKIP. Berdasarkan hasil laporan Webometrics dan 4ICU Januari 2014, PTN eks. IKIP yang menempati posisi tertinggi di antara PTN eks. IKIP lainnya adalah UPI Bandung, UNNES Semarang, UNY Yogyakarta, UNESA Surabaya, dan UM Malang. Oleh karena itu website kelima PTN tersebut dipilih sebagai sasaran penelitian. Untuk melengkapi analisis kajian, website Undiksha dijadikan sebagai bahan kaji bandingan. Hal itu dimaksudkan untuk menetapkan masukan terkait dengan kondisi website Undiksha.

\section{HASIL DAN PEMBAHASAN}

\section{Website Universitas Negeri Malang (UM) dan Desain Pola Sajian}

Bagian depan website UM cukup lamban-akses. Hal itu terjadi karena foto slide yang dipasang sebagai pembuka, terlalu berat. Beberapa foto yang menjadi catatan visual 
kegiatan utama dan terbaru, dipasang memenuhi halaman layar tampilan. Foto dengan resolusi tinggi dimaksudkan untuk menampilkan informasi yang jelas, lengkap, dan nyaman dipandang. Sebagai upaya menyajikan informasi visual yang bagus, hal tersebut bisa dimaklumi. Tetapi, risiko beratnya resolusi gambar menyebabkan masa akses website cukup panjang. Diperlukan komputer yang gegas dan sambungan internet yang lancar agar foto-foto slide tersebut bisa segera dinikmati oleh pengguna.

Gambar utama pada sudut kiri atas halaman depan website adalah simbol UM yang digandengkan dengan logotype huruf um hasil lomba, dilengkapi dengan tulisan The Learning University sebagai motto UM, bernada warna-warna pastel di atas latar warna dominan hitam. Tulisan yang berupa menu utama (pintu masuk) terdiri atas menu Depan (Beranda), Profil (tentang jatidiri universitas), Info Akademik (tentang fakultas, jurusan, dan administrasi sistem), Direktori (tentang rektorat, dekanat, dan pemimpin lembaga), serta Fasilitas (tentang fasilitas akademik dan umum) yang dilengkapi dengan menu pencarian pada bagian sebelah kanan. Secara umum tampilan menu bar ini tampak pucat, terutama karena pemilihan warna latar dan huruf yang kurang kontras, ditambah pemilihan tipe huruf jenis Arial yang tipis. Lambang dan logotif cukup tegas sebagai eyecatching pada bagian Depan atas.

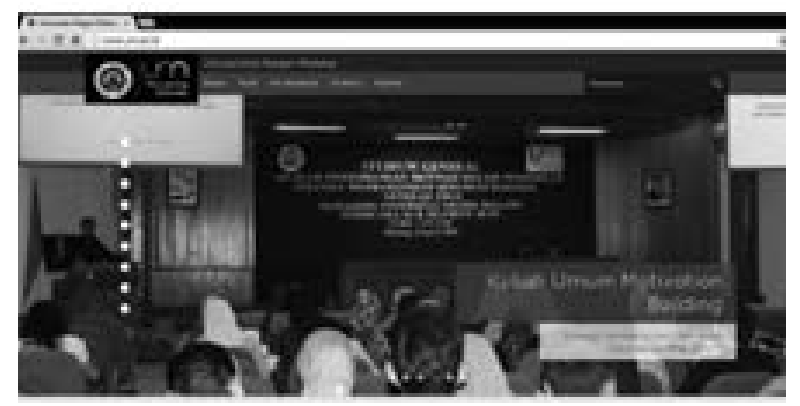

Gambar 1. Screenshot foto slide informasi visual yang memenuhi layar tampilan halaman depan, dilengkapi dengan kotak transparan informasi kegiatan yang ditampilkan.
Tabel 1. Peta Menu website Universitas Negeri Malang.

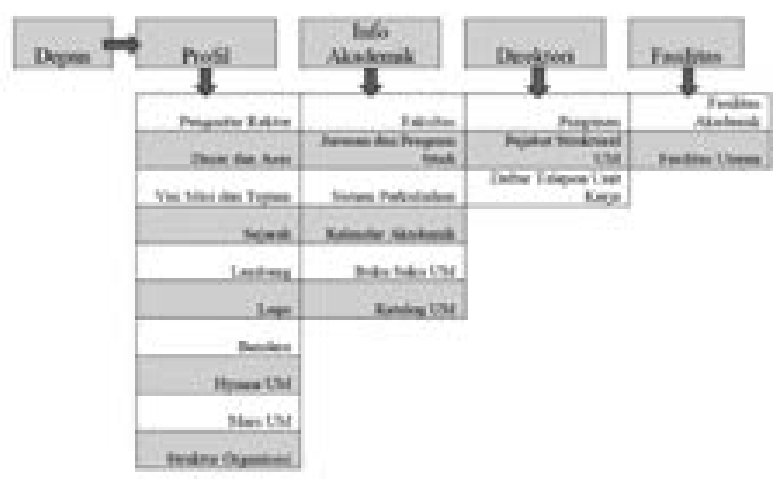

\section{Website Universitas Pendidikan Indonesia (UPI) dan Desain Pola Sajian}

Informasi yang tersaji dalam halaman "Beranda" website UPI cukup memudahkan pencarian, terutama terkait dengan berita baru, informasi seminar, dan hasil-hasil penelitian yang baru. Di samping hal itu, website UPI menyediakan akses links (tautan) ke sejumlah sub-sumber informasi UPI yaitu fakultas dan jurusan. Pilihan warna abu-abu tua pada ruang tautan cukup kontras dengan warna bagian kepala Beranda yang berwarna cokelat. Warna putih huruf-huruf yang dipasang dalam menu tautan kurang tegas, karena pilihan warna putih untuk huruf-huruf kecil, menu tautan tampil kurang tegas. Jenis huruf sans serif lebih dominan digunakan dalam tampilan antarmuka website UPI. Hanya bagian menu utama saja yang menggunakan jenis huruf Times New Roman, sementara itu pilihan huruf pada bagian turunan menunya tetap menggunakan huruf sans serif.

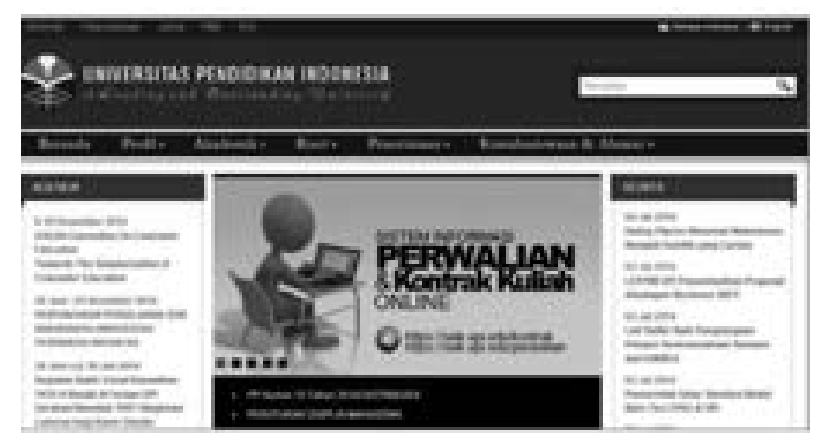

Gambar 2. Screenshot tampilan visual halaman depan-atas (Beranda) website Universitas Pendidikan Indonesia. 
Bagian pintu depan (beranda) tampilan website UPI didominasi dengan warna cokelat dan hitam. Daftar menu yang dipasang paling atas dalam tampilan Beranda adalah Webmail, Perpustakaan, Jurnal, PMB, dan SPs dengan tipe huruf Arial warna putih. Menumenu tersebut cukup jelas terbaca dalam kontras yang menyejukkan pandangan. Di bagian bawah menu tersebut dipasang ribbon yang berisi lambang UPI, ditempatkan di bagian kiri ribbon, yang dilengkapi dengan tulisan Universitas Pendidikan Indonesia A Leading and Outstanding University. Nama UPI ditulis dengan huruf tipe sans serif menggunakan warna putih, hal tersebut menyebabkan kontras yang nyaman secara visual. Tulisan brand UPI, A Leading and Outstading University, diberi warna putih kemerahan. Warna tersebut tampak kurang kontras dengan warna latar, yaitu warna cokelat lebih muda daripada menu bar. Pemilihan jenis huruf tipe kaligrafi kurang mendukung sisi keterbacaannya. Di sebelah kanannya ditempatkan kotak pencarian dengan warna latar putih dan garis kotak yang sewarna dengan menu bar.

Tabel 2. Peta menu website Universitas Pendidikan Indonesia.

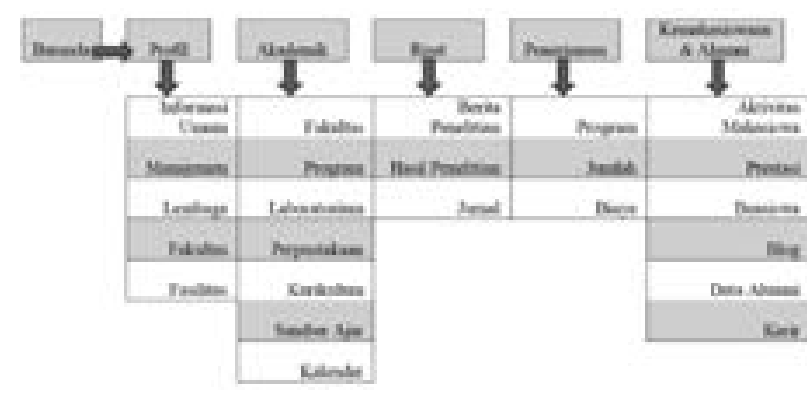

Website Universitas Negeri Yogyakarta (UNY) dan Desain Pola Sajian

Website Universitas Negeri Yogyakarta (UNY) menggunakan warna dominan biru-cerah dan putih. Pemilihan warna-warna kontras tersebut, yang digabung dengan pilihan jenis huruf sans serif bold berwarna putih dan huruf Times New Roman pada bagian tertentu, cukup nyaman dari sisi keterbacaan.

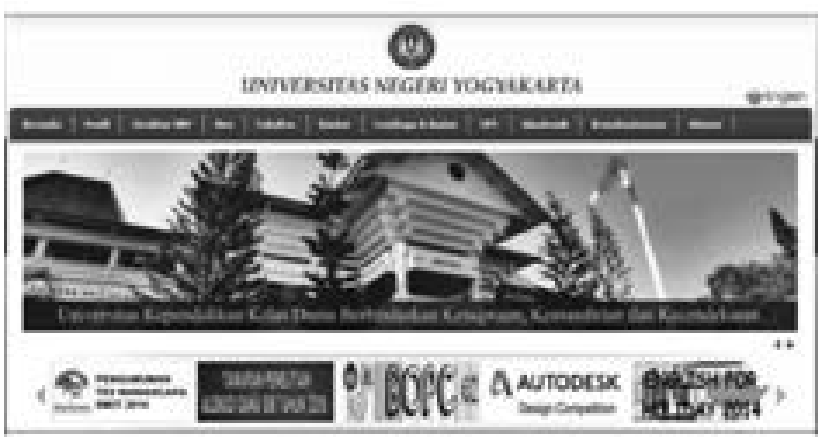

Gambar 3. Screenshot tampilan Beranda website Universitas Negeri Yogyakarta (UNY).

Gambar utama pada kepala halaman Beranda adalah simbol UNY yang dipasang menyendiri sebagai gambar inti, dilengkapi tulisan italic Universitas Negeri Yogyakarta dengan pilihan huruf sejenis Footlight. Latar belakang berupa gambar slide bangunan utama UNY dan kegiatan penting tingkat lembaga. Tulisan brand Universitas Pendidikan Kelas Dunia Berlandaskan Ketaqwaan, Kemandirian dan Kecendekiaan dipasang di bagian bawah posisi slide, di atas latar transparan berwarna hitam, dengan huruf Times New Roman berwarna kuning. Adanya banyak jenis huruf yang digunakan menyebabkan tampilan GUI bagian atas website UNY terkesan ramai, kurang tertib. Munculan banner berupa gambar dan tulisan yang dipasang pada bagian bawah gambar utama menambah hiruk-pikuk tampilan.

Tabel 3. Peta Menu website Universitas Negeri Yogyakarta.

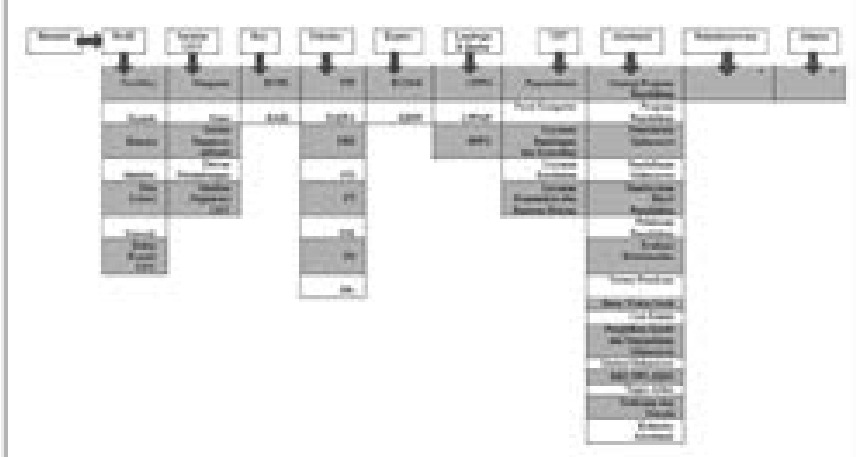

Menu Kemahasiswaan dan Alumni berupa menu langsung link ke website khusus Kemahasiswaan dan Alumni. Dua website ini 
memang dikhususkan sebagai website yang seakan terpisah dari induknya.

\section{Website Universitas Negeri Surabaya (UN- ESA) dan Desain Pola Sajian}

Tampilan antarmuka website Universitas Negeri Surabaya (UNESA) berbeda dengan tiga antarmuka website sebelumnya. Website UNESA tidak menyediakan menu utama pada Beranda. Pada bagian atas tubuh website UNESA ada ribbon berwarna cokelat muda yang berisi tulisan www.unesa.ac.id di sebelah kiri atas dan beranda, rss, dan peta situs di sebelah atas kanan. Keempat tulisan tersebut tidak berpengaruh kepada perubahan penampilan antarmuka, karena semua merupakan jalan kembali ke beranda.

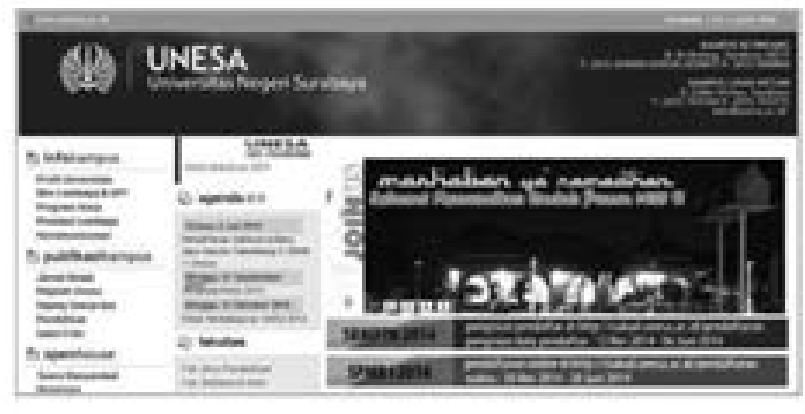

Gambar 4. Screenshot tampilan antarmuka website Universitas Negeri Surabaya.

Susunan menu website Universitas Negeri Surabaya menggunakan pola air terjun. Data ditempatkan secara berderet pada semua menu turunan yang ada di bagian bawahnya. Sementara itu, cabang-cabang menu dipasang dalam bentuk folder-folder menu, sehingga tampilan antarmuka website menjadi kurang tertib. Pola saji menu berita lead digunakan pada hampir semua tawaran informasi. Wajah website menjadi ramai dengan deretan lead berita. Secara visual hal itu menjadi kurang nyaman dipandang. Beberapa cabang menu memang dipasang dalam bentuk kalimat inti yang dilengkapi penanda akses. Tetapi, secara keseluruhan, tampilan wajah website menjadi semakin ramai.
Tabel 4. Peta Menu website Universitas Negeri Surabaya.

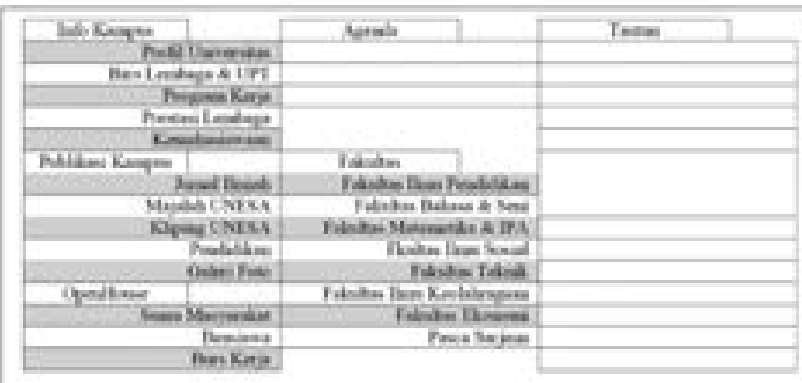

\section{Website Univesitas Negeri Semarang} (UNNES) dan Desain Pola Sajian.

Website Universitas Negeri Semarang (UNNES) memiliki tampilan antarmuka yang hampir sama dengan website milik UM, UPI, dan UNY, yaitu ada tampilan menu utama dalam pita menu pada bagian atas Beranda. Posisi pita menu berada di bawah pita besar berwarna kuning yang menjadi tempat lambang UNNES yang ditempatkan di sisi kiri atas lengkap dengan tulisan Universitas Negeri Malang Universitas Konservasi. Sementara di sisi kanan atas pita kuning ada pilihan menu International Office dengan ruang pencarian di bawahnya.

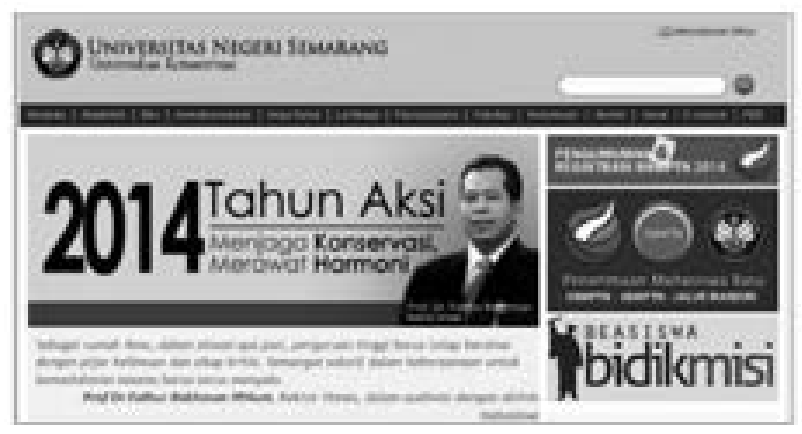

Gambar 5. Screenshot tampilan antarmuka bagian atas website Universitas Negeri Semarang.

Tampilan Beranda website Universitas Negeri Semarang tidak memiliki slide foto sebagaimana yang ditampilkan dalam website sasaran penelitian lainnya. Ada 4 banner yang dipasang cenderung berubah sejalan kondisi penting tertentu. Menu utama Beranda berisi menumenu Akademik, Biro, Kemahasiswaan, Kerja Sama, Lembaga, Pascasarjana, Fakultas, Konservasi, Alumni, Senat, E-Journal, dan PDE. 
Pola tampilannya dibangun dalam alur menu halaman bertumpuk: satu menu menuju halaman yang memiliki antarmuka dan kesatuan menu. Berbeda dengan menu turunan (drop down) pada website UM, UPI, dan UNY yang menempatkan menu utama sebagai rumah menu-menu lainnya yang bisa dipilih. Website UNNES hanya menyediakan satu pilihan langsung ke dalam halaman baru yang berisi sekumpulan menu utuh sebagaimana layaknya sebuah halaman antarmuka.

Tabel 5. Peta Menu website Universitas Negeri Semarang.

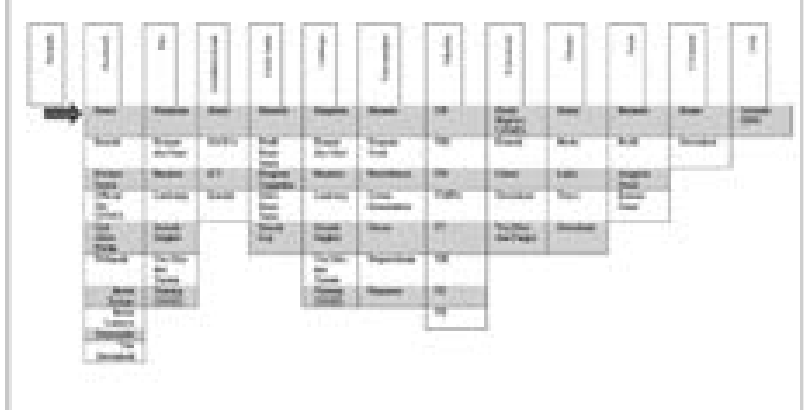

Website Universitas Pendidikan Ganesha (Undiksha) dan Desain Pola Sajian

Tampilan antarmuka website Universitas Pendidikan Ganesha lebih sederhana dibanding dengan tampilan website lainnya yang menjadi sasaran dalam penelitian ini. Warna dominan yang digunakan dalam website Undiksha adalah warna biru muda terang dan putih. Pada bagian atas dipasang pita berwarna hitam dengan tulisan sejumlah menu utama berwarna putih, terdiri atas Beranda, Berita, Agenda, Fakultas, Lembaga, Unit, Tentang, JPP, KUI, Pasca, dan Kontak. Pada ujung pita kiri terpasang lambang bahasa tampilan yang bisa dipilih berupa ikon bendera Inggris dan Indonesia. Di bawahnya dipasang lambang Undiksha dan tulisan Universitas Pendidikan Ganesha pada bagian kiri dengan font Arial berwarna hitam. Pada sisi kanan ada pilihan ikon Facebook, Twitter, email, dan kotak pencarian.

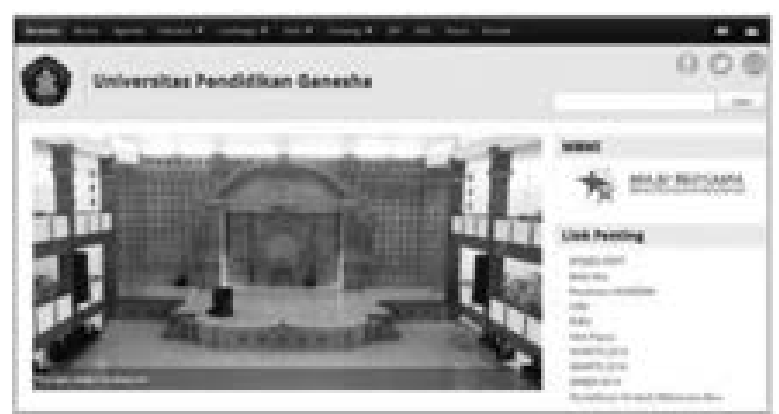

Gambar 6. Screenshot tampilan Beranda, bagian tubuh atas, website Undiksha.

Pengaksesan terhadap informasi yang disediakan dalam website Undiksha semuanya mengharuskan proses download. Berita singkat maupun panjang ditampilkan dengan pola download. Padahal, biasanya pengunjung memerlukan informasi sekadar ingin tahu isi berita sekilas, ketika hal itu dianggap penting baru melakukan proses download. Hal tersebut tampaknya mengindikasikan bentuk layanan yang kurang memberi kenyamanan bagi pengunjung. Pilihan pola yang sama diterapkan pada menu Agenda. Semua berita tentang agenda kegiatan seperti seminar, acara lomba, dan sejenisnya, harus diakses melalui cara download. Sementara itu, arsip informasi menjadi sulit untuk diakses, karena yang ditampilkan pada halaman yang terbuka sebatas yang bisa ditampung dalam kuota halaman.

Tabel 6. Peta Menu website Universitas Pendidikan Ganesha.

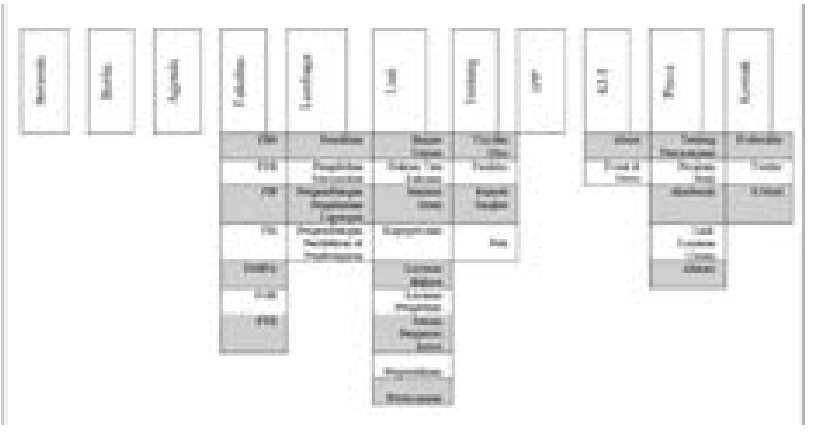

\section{Sarana dan Menu Layanan Untuk Pengun- jung Website}

Sejumlah sarana dan menu layanan untuk pengunjung website yang menarik sebagai bagian dari 6 website sasaran penelitian ini 
di antaranya adalah sebagai berikut.

Tampilan visual website yang megah dan menarik bisa didapatkan dari penempatan slide dengan foto resolusi tinggi bagian Depan website Universitas Negeri Malang. Foto-foto kegiatan rutin di-update sejalan dengan catatan kegiatan-kegiatan baru yang mereka laporkan. Tetapi, pola ini memperlamban akses ke dalam website. Pola slide yang menarik dan tetap menunjukkan kondisi akses yang gegas adalah yang ditampilkan dalam website UPI. Hal itu didapat dari pengurangan ukuran fotofoto slide yang ditampilkan, tanpa kehilangan kesan megah antarmuka beranda website. Yang bisa dikategorikan kurang menarik adalah tampilan foto slide kegiatan pada website UNY dan Undiksha yang miskin perubahan, tanpa update gambar (selama kegiatan penelitian ini dilakukan). Sementara itu, tampilan website lainnya bisa dikategorikan sebagai sesuatu yang biasa saja dengan berbagai informasi slide yang tetap ter-update, sekalipun tampilan utamanya kurang menarik.

Agihan data jalur cepat melalui jaringan internet, yang tidak memerlukan mejameja dalam kantor yang kerap memperlambat lalulintas informasi dan informasi berbasis lembaran kertas yang dianggap kurang efektif, mulai diganti dengan agihan informasi digital. Wajah layanan lembaga sangat kentara dalam tampilan antarmuka website-nya untuk keperluan ini. Sebagai contoh, informasi agenda kegiatan rutin pada website UM dan UPI tampil secara dinamis di ruang Beranda mereka. Beranda website UNY, UNESA, dan UNNES menjadi tempat "pamer" berita, sehingga banyak informasi yang menjadi tumpang-tindih. Sumber berita yang sama bisa ditemukan dan menu dan submenu yang berbeda. Sementara itu, Beranda website Undiksha terkesan kurang menyediakan keragaman informasi. Pola menu tulisan rata-rata menjadi pilihan pengembang website, sehingga halaman antarmuka menjadi sesak dengan tulisan. Diseminasi hasil kegiatan ilmiah, penelitian, pengabdian, maupun karya-karya pemikiran dan hasil temuan lainnya, pada sejumlah website cukup memanjakan pengunjung. Pola tampilan download, hampir semua dipakai dalam website sasaran penelitian ini. Pola ini, tampaknya kurang menyenangkan bagi pengguna. Setiap pengguna mengakses informasi, informasi tersebut harus didapat melalui proses download, padahal tidak semua informasi perlu di-download, cukup dilihat selintas sisi penting isinya. Ada hal menarik yang disediakan dalam layanan informasi ilmiah website UPI. Mereka menyediakan layanan data berupa menu Directory File. Menu ini berisi informasi semua karya ilmiah milik dosen UPI, berupa laporan hasil penelitian, laporan hasil pengabdian, artikel, bahan ajar, bahkan skripsi, tesis, dan (ada juga) disertasi. Materi tulisan dalam jurnal, dalam website UPI, UM, dan UNNES, beberapa periode bisa diakses dalam full-text dengan format .pdf. Website UNNES memiliki layanan khusus untuk mengelola urusan skripsi, tesis, dan disertasi. Dalam layanan ini, sekalipun yang mendapatkan akses adalah sivitas akademikanya, tampak ada ketertiban urusan pengelolaan karya ilmiah hingga urusan pembimbingan pun diatur di dalam menu ini.

Website UM dan UPI menyediakan akses bagi masyarakat selain warga perguruan tinggi. Sarana dialog disediakan dalam bentuk komentar dan pertanyaan seputar layanan administrasi pendaftaran calon mahasiswa baru. Yang lebih unik adalah layanan download game dan freeware pada website UM. Karya mahasiswa berupa software hasil pemrograman yang bersifat freeware maupun open source disediakan untuk diakses oleh siapapun. Khusus tentang hal ini, tampaknya akan mengundang pengunjung remaja yang akan memiliki "waktu panjang" dalam memanfaatkan website hingga mereka menjadi mahasiswa. Pada website lainnya, ada juga layanan lomba yang pelaksanaannya menyertakan layanan vendor software terkenal kelas dunia.

\section{Bahan Ajar Desain Komunikasi Visual Ber- basis Pendidikan Karakter}

Karakter bangsa dibangun dari nilai etika inti (core ethical values) yang bersumber dari nilai-nilai agama, falsafah negara, dan budaya (Hasanah, 2012: 209). Hal inilah yang 
kemudian melahirkan istilah Etnopedagogi, yaitu praktek pendidikan berbasis kearifan lokal (Alwasilah, 2009: 16).

Pasal 1 (3) dan 3 UU No. 20/2003, adalah landasan legal formal tentang pendidikan karakter dalam Sisdiknas. Tiga hal yang menjadi inti masalah dalam pasal dan ayat tersebut, yaitu: “...(1) watak dan peradaban bangsa yang bermartabat yang berlandaskan nilai-nilai Pancasila dan agama sebagai tujuan eksistensial pendidikan, yang (2) melandasi pencerdasan kehidupan bangsa sebagai tujuan kolektif yang di dalamnya mengandung kecerdasan kultural, karena kecerdasan kehidupan bangsa bukanlah agergasi kecerdasan perorangan atau individual, dan (3) melalui pengembangan potensi peserta didik sebagai tujuan individual. Tiga ranah tujuan ini harus dicapai secara utuh melalui proses pendidikan dalam berbagai jalur dan jenjang" (dikutip oleh Kartadinata, 2012).

Ada delapan belas nilai yang bersumber dari agama, Pancasila, budaya, dan tujuan pendidikan nasional (Pusat Kurikulum, 2009) yang ditetapkan sebagai gambaran modal dasar yang harus dikembangkan dalam pengelolaan pembelajaran. Kedelapan belas nilai tersebut adalah: 1) religius, 2) jujur, 3) toleran, 4) disiplin, 5) kerja keras, 6) kreatif, 7) mandiri, 8) demokratis, 9) rasa ingin tahu, 10) semangat kebangsaan, 11) cinta tanah air, 12) menghargai prestasi, 13) bersahabat/kounikatif, 14) cinta damai, 15) gemar membaca, 16) peduli lingkungan, 17) peduli sosial, dan 18) tanggung jawab. Semua nilai tersebut memerlukan tafsir ulang sejalan dengan kondisi lingkungan tempat pembelajaran. Tujuan kolektif yang diwarnai oleh nilai-nilai etika inti tersebut adalah tujuan yang harus diupayakan muncul mewarnai kehidupan berbangsa, sehingga karakter bangsa yang didambakan bisa menjadi milik bersama, menjadi nilai yang diakui dan didukung secara bersama-sama.

Etnopedagogi yang mengandalkan nilai etika inti dalam pembelajaran. Dalam laporan sosialisasi Kurikulum 2013 (K-13) di Langsa, Aceh, (http://www.majalahguruku. com/index.php/componenet/k2/item/183kurikulum-2013-kembangkan-kreativitas, di- akses 25 Oktober 2014, pukul 12.30), Menteri Pendidikan menegaskan bahwa: "Pendidikan karakter, akan lebih banyak dipelajari siswa di tingkat sekolah dasar dimulai sejak dini, semakin tinggi jenjangnya, pelajaran terkait pendidikan karakter berkurang dan diganti dengan pelajaran keilmuan. Dalam kurikulum baru untuk tingkat SD hanya ada enam mata pelajaran, yakni Agama, PPKN, Bahasa Indonesia, Matematika, Seni Budaya, serta Pendidikan Jasmani dan Kesehatan. IPA diintegrasikan dengan pelajaran lain. Demikian pula dengan Pendidikan Jasmani dan Kesehatan (Penjaskes) juga diintegrasikan dengan penerapan nilai dan karakter agar mendorong siswa kerja keras dan cinta Tanah Air".

Tiga kondisi yang bisa dikemukakan sebagai bahan pertimbangan dalam pelaksanaan pembelajaran pendidikan karakter di perguruan tinggi adalah: 1) pendekatan integratif dalam semua mata pelajaran yang dibangun dalam budaya satuan pendidikan dan dilaksanakan dalam kegiatan kokurikuler maupun ekstrakurikuler agar menjadi pembiasaan perilaku; 2) keteladanan dari tenaga pendidikan dan tenaga kependidikan; dan 3) pendidikan karakter di perguruan tinggi bersifat kajian keilmuan (Jajang, 2013: 29).

Berdasarkan sejumlah data hasil analisis di atas, bisa dikemukakan sejumlah kemungkinan pilihan pola yang bisa digunakan dalam kegiatan penyusunan materi ajar perancangan website. Beberapa hal penting tentang hal tersebut dibahas dalam uraian berikut.

Kajian awal berbasis penelitian kecil, tampaknya harus dilakukan oleh mahasiswa dalam setiap penggalian ide dalam menyelesaikan karya mereka. Perancangan website, misalnya, lebih memerlukan pendekatan komunikasi visual daripada sekadar nilai-nilai estetis. Banyak pola perancangan website yang bisa dibuat, tetapi perilaku biasa "serbagampang" bisa diperhitungkan sebagai salah satu pertimbangan pola rancangan. Misalnya, ketika pengunjung website mencari informasi penting tentang laporan karya ilmiah, informasi tersebut ditampilkan di tempat yang gampang diakses. Penempatan informasi di tempat yang berlapis-lapis, terutama informa- 
si utama yang diperlukan oleh rata-rata pengunjung, akan mengurangi minat pencarian mereka. Di samping itu, pola download untuk setiap informasi menjadi sangat menjengkelkan pengunjung, karena tidak semua informasi dianggap penting untuk di-download. Pola tampilan lengkap bisa menjadi daya tarik bagi pengunjung. Apalagi layanan yang tidak rumit dengan berbagai registrasi dan keharusan memasukkan kode, sangat disukai oleh pengunjung website.

Karakter utama masyarakat Indonesia adalah cenderung suka yang serba free, oleh karena itu, layanan informasi gratis penting dipertimbangkan dipasang dalam tampilan antarmuka website. Freewarefiles.com adalah salah satu layanan software gratis yang aman, legal, dan menarik. Alamat url tersebut bisa menjadi salah satu pilihan link yang ditawarkan sebagai layanan. Masih banyak layanan gratis lainnya yang bisa diakses dengan cara memasang alamatnya dalam tampilan utama website.

Salah satu bahan penilaian yang disasar oleh Webometrics dan 4ICU adalah banyaknya link karya ilmiah yang dimanfaatkan oleh pengunjung. Hal ini sangat penting, bahwa karya ilmiah yang di-share kepada pengunjung, tidak cukup sekadar abstrak. Full text, biasanya dalam format .pdf kerap menjadi pilihan pengelola website dalam menawarkan materi ini. Sekalipun tidak ada lagi format file yang dianggap sangat aman dari proses copypaste, bukti upload menjadi catatan penting yang bisa menjadi informasi kepemilikan naskah tertentu. Oleh karena itu, peng-upload pertama cenderung didata sebagai pemilik bahan unggahan.

Posisi fitur navigasi yang bisa dipilih dalam pola website sangat bervariasi. Navigasi di atas (top navigation), biasa digunakan dalam website yang memiliki banyak menu dan fasilitas. Navigasi jenis ini cukup menghemat tempat, biasanya disusun dalam pola teks tanpa ikon atau image. Navigasi di kiri (left navigation), di kanan (right navigation), dan navigasi bebas (free navigation) adalah jenis navigasi lainnya yang bisa disesuaikan dengan keperluan perancangan website.
Pembahasan elemen visual terhadap sebuah produk rancangan bisa dianalisis secara akademis. Konsep komposisi adalah salah satu di antaranya yang bisa digunakan dalam pengukuran. Oleh karena itu, penggunaan pendekatan analisis visual, dalam hal ini masalah komposisi, adalah melalui penafsiran unsurunsur karya sebagai upaya dalam memahami makna di balik hal-hal yang visual. Bahkan sisi fungsional objek, menyangkut kenyamanan penggunaan sarana layanan informasi data, secara visual bisa juga tampak dalam tampilan GUI sebuah website. Komposisi bisa dianalisis menggunakan instrumen analisis menyangkut penempatan tombol menu, pemetaan jalur informasi, sarana yang disediakan oleh pengelola website, dan menu layanan data yang dipasang di halaman GUI website. Page Rank yang diberikan oleh Google kepada sebuah website adalah berdasarkan penilaian kualitas artikel, akses website serta jumlah konten yang ada di sebuah website. Jumlah website/domain dari luar universitas yang memberikan link kepada sebuah website diukur dengan Majestic SEO Referring Domain. Masalah-masalah yang terkait dengan bahan penilaian tadi, salah satu dan paling utama sebagai daya tarik akses sebuah website, adalah tata visual dan layanan yang tampak dalam tampilan antarmuka.

\section{PENUTUP}

\section{Simpulan}

Berdasarkan hasil analisis data penelitian yang telah dilakukan, hasil penelitian dapat disimpulkan sebagai berikut.

Pertama. Tampilan visual GUI website PTN eks. IKIP periode Januari - Juni tahun 2014 dalam pola tertentu memiliki sejumlah kesamaan. Pola susun pita menu dan isi menu utama pada website sasaran penelitian menunjukkan pola yang hampir mirip. Pola tampilan slide foto kegiatan, meskipun dalam ukuran tampilan menunjukkan perbedaan, posisi dan polanya seakan mengikuti konvensi tertentu.

Kedua. Sarana layanan untuk pengunjung website menunjukkan hal yang hampir sama. Pola menu utama dipasang di bagian atas tubuh website. Pola turunan menu semua 
menggunakan menu tulisan dengan pola turun air terjun. Dari menu-menu utama yang dipasang di bagian atas, perngunjung bisa mengakses banyak informasi tentang lembaga pemilik website maupun informasi isi jurnal. Khusus untuk isi jurnal, tidak semua websitesasaran penelitian ini menyediakan sarana download full text.

Ketiga. Desain pola sajian halaman GUI website UM, UPI, UNNES, UNY, UNESA, dan Undiksha Januari-Juni tahun 2014 menunjukkan pola visual yang hampir sama. Perbedaan yang mencolok adalah pada penyebaran menu informasi tambahan. Beberapa website menempatkan informasi untuk umum, seperti berita, agenda kegiatan, maupun informasi kegiatan ilmiah, secara terpisah dari menu utama. Ada juga yang menempatkannya berulang di beberapa tempat yang berbeda dengan isi yang hampir sama. Secara umum, pola sajian halaman GUI menggunakan pola menu turunan air terjun, dengan menu utama ditempatkan di bagian tubuh atas website. Menu tambahan ditempatkan tersebar di bagian tubuh website. Bagian bawah tubuh website rata-rata digunakan untuk menempatkan menu yang berulang. Beberapa website berisi halaman yang kurang efektif penggunaannya bagi pengunjung, yaitu tidak menempatkan tombol kembali ke halaman Beranda/Depan yang jelas.

\section{Saran}

Saran untuk peneliti lanjutan, masih banyak permasalahan yang harus diteliti lanjut terkait dengan 1) efektivitas menu, 2) efektivitas tawaran akses data, 3) efektivitas pola unduhan yang disediakan untuk pengunjung website, dan 4) kemudahan me-link ke website lainnya yang bisa diakses ketika mengunjungi website yang bersangkutan.

Saran untuk pengelola website mengacu kepada materi penilaian Webometrics dan 4ICU adalah terkait dengan penempatan menu akses ke isi jurnal. Akses jurnal sebaiknya ditempatkan pada posisi lapisan terluar tampilan GUI agar mudah diakses. Pola download karya ilmiah yang disediakan secara full text menjadi pilihan yang dianggap sangat efektif dalam menjaring minat pengunjung. Di samping hal itu, pola tampilan isi informasi yang terbuka lengkap, tanpa harus melalui proses download, adalah bentuk tampilan yang memudahkan pengunjung untuk mengetahui langsung isi sajian.

\section{UCAPAN TERIMA KASIH}

Terima kasih kepada Universitas Pendidikan Ganesha yang telah memberikan kontribusi dalam penelitian, didanai dari Daftar Isian Pelaksanaan Anggaran (DIPA) Undiksha sesuai dengan surat Nomor: DIPA023.04.2.5522581/2014 Revisi ke-3, tanggal: 06 Juni 2014.

\section{DAFTAR PUSTAKA}

Alwasilah, Chaidar A. dkk. 2009. Etnopedagogi: Landasan Praktek Pendidikan dan Pendidikan Guru. Bandung: Kiblat Buku Utama.

Hasanah, Aan. 2012. Pengembangan Pendidikan Karakter Berbasis Kearifan Lokal pada Masyarakat Minoritas (Studi atas Kearifan Lokal Masyarakat Adat Suku Baduy Banten) dalam Analisis. Volume XII, no mor 1, Juni 2012.

http://blog.ub.ac.id/

http://rahmanrobotic1508.blogspot.com

http://rudinisirat.blogspot.com

http://www.4icu.org/id/

http://www.archives.gov/digital_classroom/lessons/analysis_worksheets/document.html

http://www.majalahguruku.com/index.php/componenet/k2/item/183-kurikulum-2013-kembangkan-kreativitas.

http://www.webometrics.info/en/asia/indonesia Jajang S. 2013. Redesain Bahan Pembelajaran Seni Rupa Bermuatan Pendidikan Karak ter: Penelitian Kajian Pustaka. Laporan penelitian Jurusan Pendidikan Seni Rupa, Fakultas Bahasa dan Seni, Universitas Pendidikan Ganesha.

Juju, Dominikus \& Muhammad Syukrie. 2009. Jurus Jitu Web Master Freelance. Jakarta: Elex Media Komputindo.

Kartadinata, Sunaryo. 2012. Mencari Bentuk Pendidikan Karakter Bangsa dalam 
http://file.upi.edu/browse.

php?dir =Direktori/FIP/

JUR. PSIKOLOGI PEND DAN

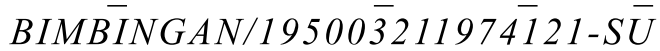

NARYO_KARTADINATA/

Purnama, Pupung Budi. 2004. Kiat Praktis Menja-

di Desainer Web Profesional. Jakarta:

Elex Media Komputindo.

Pusat Kurikulum. 2009. Pengembangan dan Pendidikan Budaya dan Karakter Bangsa:

Pedoman Sekolah. Jakarta: Puskur. 